\title{
Expanding horizons in the treatment of mantle cell lymphoma: Ibrutinib a novel BTK-targeting inhibitor
}

\author{
Sameer Dhingra ${ }^{1}$, Mamta Sachdeva ${ }^{2}$
}

${ }^{1}$ School of Pharmacy, Faculty of Medical Sciences, Eric Williams Medical Sciences Complex, Mount Hope Campus, The University of the West Indies, St. Augustine, Trinidad and Tobago ${ }^{2}$ University Institute of Pharmaceutical Sciences, UGC Center of Advanced Study (UGC-CAS) in Pharmaceutical Sciences, Panjab University, Chandigarh-160 014, India

Received: 3 December 2013

Revised: 6 December 2013

Accepted: 9 December 2013

*Correspondence to:

Sameer Dhingra,

Email: sameerdhingra78@gmail.com, sameer.dhingra@sta.uwi.edu

(C) 2014 Dhingra S et al. This is an openaccess article distributed under the terms of the Creative Commons Attribution NonCommercial License, which permits unrestricted non-commercial use, distribution, and reproduction in any medium, provided the original work is properly cited.

\begin{abstract}
Mantle cell lymphoma (MCL) is a non-Hodgkin lymphoma characterized by involvement of the lymph nodes, spleen, blood, and bone marrow with short remission duration to standard therapies and a median overall survival of 4-5 years. Small molecule inhibitors targeting dysregulated pathways (MAPK/ERK, PI3K/PKB/mTOR, JAK/STAT) have significantly improved clinical outcomes in cancer patients. Recently Bruton's tyrosine kinase (BTK), a crucial terminal kinase enzyme in the B-cell antigen receptor (BCR) signaling pathway, has emerged as an attractive target for therapeutic intervention in human malignancies and autoimmune disorders. Ibrutinib, a novel first-in-human BTK-inhibitor, has demonstrated clinical effectiveness and tolerability in clinical trials, recently been approved by FDA in the treatment of MCL.
\end{abstract}

Keywords: Mantle cell lymphoma, BTK-inhibitor, B-cell antigen receptor, Ibrutinib

\section{INTRODUCTION}

Identification of novel mediators that regulate the growth and death of cancer cells has enabled the evolution of more effective anti-cancer agents that have revolutionized therapeutic options and clinical outcomes in cancer patients. $^{1-5}$ For example, rituximab, a first-in-class chimeric monoclonal antibody targeting CD 20 molecule, has had clear impact on response rates and survival outcomes, and has become a standard component of treatment regimens for many patients with B-cell nonHodgkin's lymphomas (NHLs). ${ }^{6-8}$ Monoclonal antibodies targeting CD 19 molecule are also rapidly moving through clinical trials. ${ }^{9}$ In recent times, Bruton's tyrosine kinase (BTK), a crucial terminal kinase enzyme in the Bcell antigen receptor (BCR) signaling pathway has emerged as a novel target. ${ }^{10}$ This downstream signal transduction protein is a critical effector molecule that governs normal B-cell development, differentiation and functioning, and has also been implicated in initiation, survival and progression of mature B-cell lymphoproliferative disorders. ${ }^{11,12}$

Ibrutinib, a novel BTK-targeting inhibitor, has shown significant activities across a variety of B-cell neoplastic disorders and autoimmune diseases in preclinical models and clinical trials ${ }^{13}$ and recently got FDA approval for the treatment of MCL. This article highlights the pharmacology, clinical evidences and regulatory status of Ibrutinib with current approved indications given by FDA. 


\section{PHARMACOLOGY: IBRUTINIB}

\section{Description and chemical structure ${ }^{14}$}

Ibrutinib is an inhibitor of Bruton's tyrosine kinase (BTK). It is a white to off-white solid with the empirical formula $\mathrm{C}_{25} \mathrm{H}_{24} \mathrm{~N}_{6} \mathrm{O}_{2}$ and a molecular weight 440.50 . Ibrutinib is freely soluble in dimethyl sulfoxide, soluble in methanol and practically insoluble in water.

The chemical name for ibrutinib is 1-[(3R)-3-[4-amino-3(4-phenoxyphenyl)-1H-pyrazolo[3,4-d]pyrimidin-1-yl]-1piperidinyl]-2-propen-1-one and has the following structure:

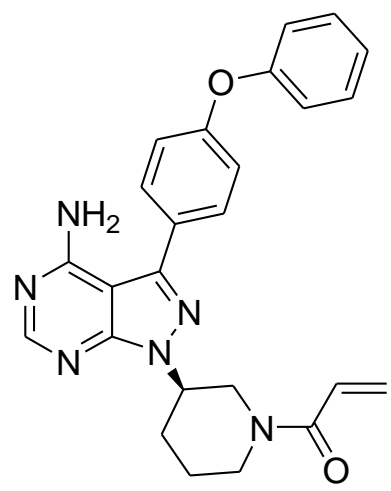

Figure 1: Chemical structure of Ibrutinib.

\section{Mechanism of action}

Ibrutinib is a small-molecule inhibitor of BTK. Ibrutinib forms a covalent bond with a cysteine residue in the BTK active site, leading to inhibition of BTK enzymatic activity. BTK is a signaling molecule of the B-cell antigen receptor (BCR) and cytokine receptor pathways. BTK's role in signaling through the B-cell surface receptors results in activation of pathways necessary for B-cell trafficking, chemotaxis, and adhesion. Nonclinical studies show that ibrutinib inhibits malignant B-cell proliferation and survival in vivo as well as cell migration and substrate adhesion in vitro. ${ }^{10,15}$

\section{Pharmacodynamics}

In patients with recurrent B-cell lymphoma > 90\% occupancy of the BTK active site in peripheral blood mononuclear cells was observed up to 24 hours after ibrutinib doses of $\geq 2.5 \mathrm{mg} / \mathrm{kg} /$ day ( $\geq 175 \mathrm{mg} / \mathrm{day}$ for average weight of $70 \mathrm{~kg}$ ). ${ }^{16,17}$

\section{Pharmacokinetics $^{16,17}$}

\section{Absorption}

Ibrutinib is absorbed after oral administration with a median $\mathrm{T}_{\max }$ of 1 to 2 hours. Ibrutinib exposure increases with doses up to $840 \mathrm{mg}$. The steady-state AUC observed in patients at $560 \mathrm{mg}$ is (mean \pm standard deviation) $953 \pm 705 \mathrm{ng} \cdot \mathrm{h} / \mathrm{mL}$. Administration with food increases ibrutinib exposure approximately 2-fold compared with administration after overnight fasting.

\section{Distribution}

Reversible binding of ibrutinib to human plasma protein in vitro was $97.3 \%$ with no concentration dependence in the range of 50 to $1000 \mathrm{ng} / \mathrm{mL}$. The apparent volume of distribution at steady state $(\mathrm{Vd}, \mathrm{ss} / \mathrm{F})$ is approximately $10000 \mathrm{~L}$.

\section{Metabolism}

Metabolism is the main route of elimination for ibrutinib. It is metabolized to several metabolites primarily by cytochrome P450, CYP3A, and to a minor extent by CYP2D6. The active metabolite, PCI-45227, is a dihydrodiol metabolite with inhibitory activity towards BTK approximately 15 times lower than that of ibrutinib. The range of the mean metabolite to parent ratio for PCI45227 at steady-state is 1 to 2.8 .

\section{Elimination}

Apparent clearance (CL/F) is approximately $1000 \mathrm{~L} / \mathrm{h}$. The half-life of ibrutinib is 4 to 6 hours. Ibrutinib, mainly in the form of metabolites, is eliminated primarily via feces. After a single oral administration of radiolabeled [14C]-ibrutinib in healthy subjects, approximately $90 \%$ of radioactivity was excreted within 168 hours, with the majority (80\%) excreted in the feces and less than $10 \%$ accounted for in urine. Unchanged ibrutinib accounted for approximately $1 \%$ of the radiolabeled excretion product in feces and none in urine, with the remainder of the dose being metabolites.

\section{CLINICAL STUDIES}

\section{Mantle cell lymphoma}

The safety and efficacy of ibrutinib in patients with MCL who have received at least one prior therapy were evaluated in an open-label, multi-center, single-arm trial of 111 previously treated patients. The median age was 68 years (range, 40 to 84 years), $77 \%$ were male, and $92 \%$ were Caucasian. At baseline, $89 \%$ of patients had a baseline ECOG performance status of 0 or 1 . The median time since diagnosis was 42 months, and median number of prior treatments was 3 (range, 1 to 5 treatments), including $11 \%$ with prior stem cell transplant. At baseline, $39 \%$ of subjects had at least one tumor $\geq 5 \mathrm{~cm}$, $49 \%$ had bone marrow involvement, and $54 \%$ had extranodal involvement at screening.

Ibrutinib was administered orally at $560 \mathrm{mg}$ once daily until disease progression or unacceptable toxicity. Tumor response was assessed according to the revised International Working Group (IWG) for non-Hodgkin's 
lymphoma (NHL) criteria. The primary endpoint in this study was investigator-assessed overall response rate (ORR). Responses to ibrutinib are shown in Table 1.

Table 1: Overall Response Rate (ORR) and Duration of Response (DOR) based on investigator assessment in patients with mantle cell lymphoma.

\begin{tabular}{|ll|}
\hline & Total $(\mathrm{N}=111)$ \\
\hline ORR $(\%)$ & 65.8 \\
\hline 95\% CI $(\%)$ & $(56.2,74.5)$ \\
\hline CR $(\%)$ & 17.1 \\
\hline PR $(\%)$ & 48.6 \\
\hline $\begin{array}{l}\text { Median DOR months } 95 \% \\
\text { CI }\end{array}$ & $17.5(15.8, \mathrm{NR})$ \\
\hline
\end{tabular}

$\mathrm{CI}=$ confidence interval $; \mathrm{CR}=$ complete response $; \mathrm{PR}=$ partial response; $\mathrm{NR}=$ not reached

An Independent Review Committee (IRC) performed independent reading and interpretation of imaging scans. The IRC review demonstrated an ORR of $69 \%$. The median time to response was 1.9 months. ${ }^{13-17}$

\section{Lymphocytosis}

Upon initiation of ibrutinib, a temporary increase in lymphocyte counts (i.e., $\geq 50 \%$ increase from baseline and above absolute lymphocyte count of $5,000 / \mathrm{mcL}$ ) occurred in $33 \%$ of patients in the MCL study. The onset of isolated lymphocytosis occurs during the first few weeks (median time 1.1 weeks) of ibrutinib therapy and resolves by a median of 8 weeks. ${ }^{18}$

\section{REGULATORY STATUS}

On November 13, 2013, the U. S. Food and Drug Administration granted accelerated approval to ibrutinib for the treatment of patients with MCL who have received at least one prior therapy. ${ }^{19}$

\section{INDICATIONS}

Ibrutinib is indicated for the treatment of patients with MCL who have received at least one prior therapy. This indication is based on overall response rate. An improvement in survival or disease-related symptoms has not been established. ${ }^{19}$

\section{DOSAGE AND ADMINISTRATION}

\section{Dosage for mantle cell lymphoma}

The recommended dose of ibrutinib for MCL is $560 \mathrm{mg}$ (four $140 \mathrm{mg}$ capsules) orally once daily. ${ }^{20}$

\section{Dosing guidelines}

Ibrutinib is administered orally once daily at approximately the same time each day. Capsules are swallowed whole with water. ${ }^{20}$

\section{Missed dose}

If a dose of ibrutinib is not taken at the scheduled time, it can be taken as soon as possible on the same day with a return to the normal schedule the following day. Extra doses of ibrutinib should not be taken to make up for the missed dose. ${ }^{20}$

\section{Dose modifications for adverse reactions}

Interrupt ibrutinib therapy for any Grade 3 or greater nonhematological, Grade 3 or greater neutropenia with infection or fever, or Grade 4 hematological toxicities. Once the symptoms of the toxicity have resolved to Grade 1 or baseline (recovery), ibrutinib therapy may be reinitiated at the starting dose. If the toxicity reoccurs, reduce dose by one capsule (140 mg per day). A second reduction of dose by $140 \mathrm{mg}$ may be considered as needed. If these toxicities persist or recur following two dose reductions, discontinue ibrutinib. ${ }^{20}$ Recommended dose modifications for these toxicities are given in Table 2.

\section{Table 2: Recommended dose modifications for} toxicities.

\begin{tabular}{|ll|}
\hline $\begin{array}{l}\text { Toxicity } \\
\text { Occurrence }\end{array}$ & $\begin{array}{l}\text { MCL Dose Modification } \\
\text { After Recovery Starting Dose } \\
\mathbf{5} \mathbf{5 6 0} \mathbf{~ m g}\end{array}$ \\
\hline First & Restart at $560 \mathrm{mg}$ daily \\
\hline Second & Restart at $420 \mathrm{mg}$ daily \\
\hline Third & Restart at $280 \mathrm{mg}$ daily \\
\hline Fourth & Discontinue ibrutinib \\
\hline
\end{tabular}

\section{ADVERSE EFFECTS}

The most commonly occurring adverse reactions $(\geq 20 \%)$ were thrombocytopenia, diarrhea, neutropenia, anemia, fatigue, musculoskeletal pain, peripheral edema, upper respiratory tract infection, nausea, bruising, dyspnea, constipation, rash, abdominal pain, vomiting and decreased appetite..$^{20,21}$

The most common Grade 3 or 4 non-hematological adverse reactions $(\geq 5 \%$ ) were pneumonia, abdominal pain, atrial fibrillation, diarrhea, fatigue, and skin infections. $^{20,21}$ 


\section{WARNINGS AND PRECAUTIONS}

\section{Hemorrhage}

Five percent of patients with MCL had Grade 3 or higher bleeding events (subdural hematoma, gastrointestinal bleeding, and hematuria). Overall, bleeding events including bruising of any grade occurred in $48 \%$ of patients with MCL treated with $560 \mathrm{mg}$ daily. ${ }^{20}$

The mechanism for the bleeding events is not well understood.

Consider the benefit-risk of ibrutinib in patients requiring antiplatelet or anticoagulant therapies.

Consider the benefit-risk of withholding ibrutinib for at least 3 to 7 days pre and post-surgery depending upon the type of surgery and the risk of bleeding. ${ }^{20}$

\section{Infections}

Fatal and non-fatal infections have occurred with ibrutinib therapy. At least $25 \%$ of patients with MCL had infections Grade 3 or greater NCI Common Terminology Criteria for Adverse Events (CTCAE). Monitor patients for fever and infections and evaluate promptly. ${ }^{20}$

\section{Myelosuppression}

Treatment-emergent Grade 3 or 4 cytopenias were reported in $41 \%$ of patients. These included neutropenia (29\%), thrombocytopenia (17\%) and anemia (9\%). Monitor complete blood counts monthly. ${ }^{20}$

\section{Renal toxicity}

Fatal and serious cases of renal failure have occurred with ibrutinib therapy. Treatment-emergent increases in creatinine levels up to 1.5 times the upper limit of normal occurred in $67 \%$ of patients and from 1.5 to 3 times the upper limit of normal in $9 \%$ of patients. Periodically monitor creatinine levels. Maintain hydration. ${ }^{20}$

\section{Second primary malignancies}

Other malignancies $(5 \%)$ have occurred in patients with MCL who have been treated with ibrutinib, including skin cancers $(4 \%)$, and other carcinomas $(1 \%){ }^{20}$

\section{Embryo-fetal toxicity}

Based on findings in animals, ibrutinib can cause fetal harm when administered to a pregnant woman. Ibrutinib caused malformations in rats at exposures 14 times those reported in patients with MCL receiving the ibrutinib dose of $560 \mathrm{mg}$ per day. Reduced fetal weights were observed at lower exposures. Advise women to avoid becoming pregnant while taking ibrutinib. If this drug is used during pregnancy or if the patient becomes pregnant while taking this drug, the patient should be apprised of the potential hazard to a fetus. ${ }^{20,21}$

\section{DRUG INTERACTIONS}

Ibrutinib is primarily metabolized by cytochrome $\mathrm{P} 450$ enzyme $3 \mathrm{~A}$.

\section{CYP3A inhibitors}

In healthy volunteers, co-administration of ketoconazole, a strong CYP3A inhibitor, increased $\mathrm{C}_{\max }$ and AUC of ibrutinib by 29- and 24-fold, respectively. The highest ibrutinib dose evaluated in clinical trials was $12.5 \mathrm{mg} / \mathrm{kg}$ (actual doses of $840-1400 \mathrm{mg}$ ) given for 28 days with single dose AUC values of $1445 \pm 869 \mathrm{ng} \cdot \mathrm{hr} / \mathrm{mL}$ which is approximately $50 \%$ greater than steady state exposures seen at the highest indicated dose $(560 \mathrm{mg}) .{ }^{19-21}$

Avoid concomitant administration of ibrutinib with strong or moderate inhibitors of CYP3A. For strong CYP3A inhibitors used short-term (e.g., antifungals and antibiotics for 7 days or less, e.g., ketoconazole, itraconazole, voriconazole, posaconazole, clarithromycin, telithromycin) consider interrupting ibrutinib therapy during the duration of inhibitor use. Avoid strong CYP3A inhibitors that are needed chronically. If a moderate CYP3A inhibitor must be used, reduce the ibrutinib dose. Patients taking concomitant strong or moderate CYP3A4 inhibitors should be monitored more closely for signs of ibrutinib. $^{19-21}$

Avoid grapefruit and Seville oranges during ibrutinib treatment, as these contain moderate inhibitors of CYP3A. ${ }^{20}$

\section{CYP3A inducers}

Administration of ibrutinib with strong inducers of CYP3A decrease ibrutinib plasma concentrations by approximately 10-fold. Avoid concomitant use of strong CYP3A inducers (e.g., carbamazepine, rifampin, phenytoin and St. John's Wort). Consider alternative agents with less CYP3A induction. ${ }^{20}$

\section{SPECIAL POPULATION}

\section{Pregnancy and lactation}

It has been assigned Category D in pregnancy, based on findings in animals, ibrutinib can cause fetal harm when administered to a pregnant woman. If ibrutinib is used during pregnancy or if the patient becomes pregnant while taking ibrutinib, the patient should be apprised of the potential hazard to the fetus. ${ }^{20}$

It is not known whether ibrutinib is excreted in human milk. Because many drugs are excreted in human milk and because of the potential for serious adverse reactions in nursing infants from ibrutinib, a decision should be 
made whether to discontinue nursing or to discontinue the drug, taking into account the importance of the drug to the mother. ${ }^{20}$

\section{Pediatric and geriatric use}

The safety and effectiveness of ibrutinib in pediatric patients has not been established. ${ }^{20}$

During trials, no overall differences in effectiveness were observed between elderly patients and younger patients. However, cardiac adverse events (atrial fibrillation and hypertension), infections (pneumonia and cellulitis) and gastrointestinal events (diarrhea and dehydration) occurred more frequently among elderly patients. ${ }^{20}$

\section{Renal impairment}

Ibrutinib exposure is not altered in patients with Creatinine clearance (CLcr) $>25 \mathrm{~mL} / \mathrm{min}$ as less than $1 \%$ of ibrutinib is excreted renally. However, there are no data available in patients with severe renal impairment (CLcr $<25 \mathrm{~mL} / \mathrm{min}$ ) or patients on dialysis. ${ }^{20}$

\section{Hepatic impairment}

Ibrutinib is metabolized in the liver and significant increases in exposure of ibrutinib are expected in patients with hepatic impairment. Patients with serum aspartate transaminase (AST/SGOT) or alanine transaminase $($ ALT/SGPT) $\geq 3.0 \times$ upper limit of normal (ULN) were excluded from clinical trials. There is insufficient data to recommend a dose in patients with baseline hepatic impairment. $^{20}$

\section{CONCLUSIONS}

The current body of clinical evidences indicate that ibrutinib is effective for the treatment of patients with MCL who have received at least one prior therapy as it has shown significant activities across a variety of B-cell neoplastic disorders and autoimmune diseases in preclinical models and clinical trials.

\section{Abbreviations}

MAPK: Mitogen-activated protein kinases, ERK: Extracellular signal-regulated kinases, PI3K: Phosphatidylinositide 3-kinases, PKB: Protein Kinase B, mTOR: Mammalian target of rapamycin, JAK: Janus kinase, STAT: Signal transduction and transcription, BTK: Bruton's tyrosine kinase

Funding: No funding sources Conflict of interest: None declared

Ethical approval: Not required

\section{REFERENCES}

1. Vose JM. Mantle cell lymphoma: 2012 update on diagnosis, risk-stratification, and clinical management. Am J Hematol 2012; 87(6):604-9.

2. Liu L, Wu N, Li J. Novel targeted agents for gastric cancer. J Hematol Oncol 2012; 5(1):31.

3. Lamba G, Ambrale S, Lee B, Gupta R, Rafiyath S, Liu D. Recent advances and novel agents for gastrointestinal stromal tumor (GIST). J Hematol Oncol 2012; 5(1):21.

4. Lee B, Mukhi N, Liu D. Current management and novel agents for malignant melanoma. J Hematol Oncol 2012; 5(1):3.

5. WeiSZ L, Efferth T. Polo-like kinase 1 as target for cancer therapy. Exp J Hematol Oncol 2012; 1(1):38.

6. McLaughlin P, Grillo-Lopez AJ, Link BK, Levy R, Czuczman MS, Williams ME, Heyman MR, BenceBruckler I, White CA, Cabanillas F, et al. Rituximab chimeric anti-CD20 monoclonal antibody therapy for relapsed indolent lymphoma: half of patients respond to a four-dose treatment program. J Clin Oncol 1998; 16(8):2825-2833.

7. Colombat P, Salles G, Brousse N, Eftekhari P, Soubeyran P, Delwail V, Deconinck E, Haioun C, Foussard C, Sebban C, et al. Rituximab (anti-CD20 monoclonal antibody) as single first-line therapy for patients with follicular lymphoma with a low tumor burden: clinical and molecular evaluation. Blood 2001; 97(1):101-106.

8. Cang S, Mukhi N, Wang K, Liu D. Novel CD20 monoclonal antibodies for lymphoma therapy. J Hematol Oncol 2012; 5:64.

9. Wang K, Wei G, Liu D. CD19: a biomarker for B cell development, lymphoma diagnosis and therapy. Exp J Hematol Oncol 2012, 1(1):36.

10. Herman SE, Gordon AL, Hertlein E, Ramanunni A, Zhang X, Jaglowski S, Flynn J, Jones J, Blum KA, Buggy JJ, et al. Bruton tyrosine kinase represents a promising therapeutic target for treatment of chronic lymphocytic leukemia and is effectively targeted by PCI-32765. Blood 2011; 117(23):6287-6296.

11. Kuppers R. Mechanisms of B-cell lymphoma pathogenesis. Nat Rev Cancer 2005; 5(4):251-262.

12. Honigberg LA, Smith AM, Sirisawad M, Verner E, Loury D, Chang B, Li S, Pan Z, Thamm DH, Miller $\mathrm{RA}$, et al. The Bruton tyrosine kinase inhibitor PCI32765 blocks B-cell activation and is efficacious in models of autoimmune disease and B-cell malignancy. Proc Natl Acad Sci USA 2010; 107(29):13075-13080.

13. Akinleye A, Chen Y, Mukhi N, Song Y, Liu D. Ibrutinib and novel BTK inhibitors in clinical development. J Hematol Oncol 2013; 6:59

14. National Cancer Institute at the National Institutes of Health. Available

http://www.cancer.gov/drugdictionary?cdrid=638648 . Accessed 15 July 2013.

15. Betty Y. Chang, Michelle Francesco, Martin F.M. De Rooij, et al. Egress of CD19+ CD5+ cells into 
peripheral blood following treatment with the BTK inhibitor ibrutinib in mantle cell lymphoma patients. Blood 2013; 02-482125.

16. Byrd JC, Furman RR, Coutre SE, Flinn IW, Burger JA, Blum KA, et al. Targeting BTK with ibrutinib in relapsed chronic lymphocytic leukemia. N Engl J Med. 2013; 369:32-42.

17. Advani RH, Joseph JB, Jeff PS, Sonali MS, Thomas $\mathrm{EB}$, Barbara $\mathrm{G}$, et al. Bruton tyrosine kinase inhibitor ibrutinib (PCI-32765) has significant activity in patients with relapsed/refractory B-cell malignancies. J Clin Oncol 2013; 31:88-94.

18. Chavez JC, Eva S, Javier PI. Ibrutinib: an evidencebased review of its potential in the treatment of advanced chronic lymphocytic leukemia. Core evidence $2013 ; 8: 37$.

19. U.S. FDA. Available at http://www.fda.gov/Drugs/InformationOnDrugs/App rovedDrugs/ucm374857.htm. Last accessed November 30, 2013.

20. U.S. FDA. Available at http://www.accessdata.fda.gov/drugsatfda_docs/label /2013/205552lbl.pdf.

21. http://www.medscape.com/viewarticle/806684.

doi:10.5455/2319-2003.ijbcp20140231

Cite this article as: Dhingra $S$, Sachdeva $M$.

Expanding horizons in the treatment of mantle cell lymphoma: Ibrutinib a novel BTK-targeting inhibitor. Int J Basic Clin Pharmacol 2014;3:249-54. 